\title{
La ciudad movimiento: cotidianidades, afectividades corporizadas y redes topológicas
}

\section{ALICIA LINDÓN}

alicia.lindon@gmail.com - Universidad Autónoma Metropolitana, México

Fecha de recepción: 13 de junio de 2017

Fecha de aceptación: 21 de junio de 2017

\section{RESUMEN}

La pregunta principal de este artículo es la siguiente: ¿cómo estudiar la dimensión espacial de la ciudad y la vida urbana? Antes que presentar un estudio de caso, en estas páginas, se desarrolla un planteamiento teórico-metodológico para abordar el caso de las grandes ciudades. El objetivo principal es ofrecer una aproximación multidimensional y aterrizada de la construcción social de la ciudad movimiento.

La primera parte revisa los diferentes aspectos de la perspectiva de la ciudad como espacio movimiento. La segunda parte analiza la componente de las prácticas y la subjetividad espacial integrada en esta concepción dela ciudad como espacio movimiento. El tercer apartado aborda las afectividades y la corporeidad dela ciudad movimiento. Posteriormente, se presenta la perspectiva situacional y las redes topológicas como formas de aprehender fragmentos densos de lo urbano que integren lo planteado en los apartados previos. Para cerrar con unas reflexiones finales que destacan tanto la potencialidad de tal aproximación como sus limitaciones.

PALABRAS CLAVE: sujeto, vida urbana, prácticas, subjetividades, imaginarios urbanos.

\section{ABSTRACT}

The main question of this article is the following: how to study the spatial dimension of the city and urban life? Before that submit a case study, in these pages, develops a theoretical-methodological approach for dealing with large cities. The main objective is to offer a multidimensional and grounded perspective of the social construction of the city movement.

The first part reviews the different aspects of the perspective of the city as a space movement. The second part analyzes the everyday practices and the spatial subjectivity of this conception of the city as a space movement. The third section, deals with the affections and bodily of the city movement. Then comes the situational perspective and topological networks as ways of apprehending dense urban fragments that integrate the issues raised in the previous paragraphs. To close with a few final thoughts that highlight both the potential of such an approach and its limitations

KEYWORDS: subject, urbanlife, practices, subjectivities, urban imaginaries. 


\section{PRESENTACIÓN}

El tema más amplio que nos convoca es la ciudad contemporánea, tanto en su materialidad como en sus aspectos no materiales. Este tema general se replantea hacia la dimensión espacial de la ciudad y la vida urbana. Más específicamente, nos preguntamos ¿cómo estudiar la dimensión espacial de la ciudad y la vida urbana? Antes que presentar un estudio de caso, en estas páginas se desarrolla un planteamiento teórico-metodológico para abordar el tema en el caso de las grandes ciudades, que tiene detrás diversas investigaciones empíricas. Una preocupación de fondo de este desarrollo es aproximarnos al fenómeno sin mutilarlo por reducirlo en pos de la simplicidad.

Por la considerable diversidad de perspectivas acerca de la ciudad ylo urbano, es conveniente presentar los dos supuestos de los que se parte para explorar este dominio, y que le dan una orientación particular a este artículo. Por un lado, se asume que la ciudad y la vida urbana resultan mutiladas en su esencia misma cuando son consideradas solo como formas espaciales. Por otra parte, también se parte del reconocimiento de las sociedades urbanas como sociedades complejas, múltiples y heterogéneas. Quizás, desde una perspectiva comunicacional, estos dos presupuestos puedan resultar innecesarios por evidentes. Sin embargo, dado que el estudio de la ciudad y lo urbano no surge en el ámbito comunicacional, el sesgo hacia las formas espaciales ha estado muy presente. Por ello, consideramos importante subrayar que partimos del reconocimiento de la insuficiencia de ese énfasis tan arraigado.

Para los estudios urbanos tradicionales, considerar que la ciudad es algo más que las formas espaciales, desafía la zona de confort que largamente ha permitido utilizar esquemas analíticos simples y centrados en las formas espaciales materiales, pero muy probados en su eficiencia para estudiar desde ese ángulo la ciudad y lo urbano. Si a la integración de lo no material, que coexiste con las formas espaciales, le integramos la idea de la complejidad (el segundo supuesto), como algo propio de lo social urbano, mayor desafío implica el estudio de la ciudad y lo urbano; porque la complejidad, entre otras cuestiones, también lleva consigo un estado particular: estar haciéndose constantemente. Cabe destacar esta peculiaridad, porque la perspectiva del proceso de investigación obliga al estudioso del fenómeno a recurrir a diversos artilugios que de alguna manera hipotética fijen el objeto de estudio, que intrínsecamente se mueve de manera constante (Ibáñez, 1994).

Con este horizonte retomamos la concepción del espacio-movimiento de Nigel Thrift (2008), particularmente en términos del flujo constante de la vida cotidiana y la renombramos como la ciudad-movimiento. Cabe destacar que el movimiento incluye los desplazamientos de objetos y personas de un lugar a otro, pero no se agota en ello. Con estos antecedentes, el objetivo principal de este artículo es ofrecer una aproximación multidimensional y aterrizada 
de lo que estamos denominando como la construcción social de la ciudadmovimiento (Lindón, 2015).

Para avanzar en este rumbo, en la primera parte se revisan diferentes cuestiones puestas en juego en la perspectiva de la ciudad como espacio-movimiento. En una segunda parte se analiza la componente de las prácticas y la subjetividad espacial que conlleva nuestra concepción de la ciudad como espacio-movimiento. A continuación, en un tercer apartado, se incluyen las afectividades y la corporeidad de la ciudad-movimiento. Posteriormente, se presenta la perspectiva situacional ylas redes topológicas como formas de aprehender fragmentos densos de lo urbano que integren lo planteado en los dos apartados previos. Para cerrar con unas reflexiones finales que destacan tanto la potencialidad de tal aproximación como sus limitaciones.

\section{EL MOVIMIENTO, LA CIUDAD Y LO URBANO}

La vida urbana contemporánea está notoriamente inmersa en la aceleración, que si bien tiene un origen técnico y económico - ya que la tecnología ha permitido acortar los ciclos de producción y el consumo ha quedado contextualizado en la rápida obsolescencia de los productos- ha traspasado las fronteras de lo económico y ha envuelto lo social en sentido amplio, lo cultural, lo espacial. La aceleración es una forma de movimiento que involucra de manera central a las ciudades y la vida urbana. La obra de Harvey (1998) sobre la compresión espacio-temporal es parte del tema. La defensa de la lentitud - como discursos (Honoré, 2005) y también como acciones sociales- que se constata en diversos lugares del mundo, por ahora es una expresión de la intensidad de la aceleración. Una de las expresiones del desarrollo tecnológico sumamente involucrada en el movimiento es lo referente a los medios de transporte, que precisamente alcanzan notable desarrollo en las ciudades.

Otra expresión del movimiento en que está inmersa la vida urbana actual son los desplazamientos espaciales, particularmente los de tipo cotidiano, que los habitantes de las ciudades deben afrontar para desarrollar las actividades básicas; como las laborales, educativas, incluso las de consumo. Este énfasis en los desplazamientos cotidianos no olvida los que ocurren en otros ciclos de tiempo, como los desplazamientos a territorios más o menos lejanos, o incluso los flujos migratorios. La contraparte delos desplazamientos cotidianos deloshabitantesde las ciudades son los flujos de bienes, servicios e información. Todos estos desplazamientos son expresiones evidentes del movimiento que marca el ritmo urbano.

Las mencionadas formas del movimiento de la ciudad han sido extensamente analizadas en las últimas dos décadas. En casi todos los casos, estos movimientos suelen analizarse como si se tratara del desplazamiento de objetos. En buena medida se trata de objetos, pero incluso la movilidad cotidiana de las personas suele abordarse bajo ese cristal, así se presenta la cantidad de 
personas que se desplaza desde un punto de origen yhacia un punto de destino. Aquí, en cambio, nos interesa orientarnos a la esencia misma del movimiento, el sujeto-habitante, y sin perder el horizonte vitalista que supone todo movimiento. Es el sujeto quien manufactura las ciudades, en su materialidad. Al mismo tiempo, el sujeto, en su cotidiano modo de habitarlas, las construye socio-espacialmente al ir inscribiendo su biografía en los diversos lugares que conforman las ciudades, al ir dotando de sentidos, de sueños, fantasías, miedos, aversiones, valores y vivencias, cada rincón (Lindón, 2015). Por todo ello, el sujeto habitante de las ciudades puede ser considerado filosóficamente ${ }^{1}$ en su condición de ser como un proceso siempre en curso, entre la concienciaintuición-percepción y la realidad, abierto, sin límites. En su célebre ensayo sobre la vida en las grandes ciudades (Großstadt), escrito a inicios del siglo XX, Georg Simmel (1986) ya observaba ese proceso dinámico entre el urbanita y el entorno material de la gran ciudad, como un proceso complejo, selectivo, cambiante.

En ese proceso siempre en curso, el urbanita se enfrenta no sólo a la heterogeneidad del entorno, sino a la necesidad de comprenderlo. La comprensión misma que hace el sujeto habitante de sus lugares en la ciudad constituye una forma de movimiento, porque lleva consigo procesos de cognición espacial de un entorno que es múltiple. En otras palabras, se trata de la elaboración interna de lo externo al sujeto. Además, ocurre que ese entorno espacial posee muchas lógicas propias de movimiento, por lo que induce la producción de nuevas comprensiones de manera constante, ya que ese mundo externo que el urbanita elabora internamente está en movimiento incesante. En estos procesos de comprensión del entorno, los sujetos van dotando de significados, valores y memoria cada lugar donde se hayan inscrito acontecimientos de su propia trayectoria biográfica.

Frecuentemente, cuando se analiza al sujeto tiende a enfatizarse la capacidad cognitiva, la comprensión del mundo, o bien, las prácticas, mientras que suele soslayarse el cuerpo y la corporeidad. Esta omisión es paradójica si se considera que el sujeto puede tener motricidad en virtud de poseer un cuerpo. Las acciones, las prácticas y los comportamientos son posibles por el cuerpo y a través de él. Y el cuerpo nunca está quieto, ni siquiera cuando está en reposo (Pile \& Thrift, 1995). El cuerpo es esencialmente móvil en el espacio y está dotado de movimiento ${ }^{2}$. Y por el movimiento que lo caracteriza es capaz de comunicar a los otros. Al comunicar, al expresar algo, el cuerpo adquiere corporeidad. Así, la corporeidad es el concepto asociado con el cuerpo desde la perspectiva del movimiento. Por todo ello, resulta paradójico que los estudios

1 Particularmente en la tradición bergsoniana y deleuziana (Ezcurdia, 2013).

2 Quizás en este sentido resulta más específico el inglés que el español: en inglés, el primero de estos movimientos, el espacial, se refiere a través del vocablo mobility. Mientras que el segundo, el movimiento vitalista, se expresa a través del vocablo movement. En cambio, en español se utiliza la misma palabra para ambos. 
urbanos -incluso, los más sensibles al sujeto habitante, que llegan a recurrir a las emblemáticas imágenes de las ciudades como numerosas corporeidades en el espacio público- soslayen analíticamente el cuerpo y la corporeidad.

La acción, el comportamiento o las prácticas son expresiones evidentes del movimiento corporal. El ámbito del hacer constituye la forma por excelencia del movimiento que anima a la ciudad. El proceso de manufacturar el espacio urbano resulta de la multiplicidad de prácticas del sujeto. Tal como planteara Nigel Thrift, "la agencia humana debe ser vista por lo que es, un flujo continuo de conducta a través del tiempo y el espacio interpelando constantemente la estructura social" (Thrift, 1983, p. 31).

Tal como han planteado Pile y Thrift (1995), una gran parte de las acciones - o quizás todas - requieren de la colaboración de otras acciones. Por ello, los saberes encarnados en una persona y que le permiten realizar cierta acción, no sólo existen en ella como una capacidad de agencia individual. Son disposiciones encarnadas en las personas como co-agencia respecto a encadenamientos de acciones. En otras palabras, todos los movimientos corporales de un habitante están relacionados con saberes que otros también poseen y que permiten que unos y otros participen en secuencias de acciones, que en última instancia son formas de colaboración encarnadas en nosotros.

Otra expresión del movimiento del sujeto que habita la ciudad se asocia con el manejo del tiempo vivido. En el proceso de enfrentarse al entorno en cada circunstancia, en cada momento (siempre presente), espontáneamente y como parte de los procesos cognitivos, se está trayendo al presente, el pasado, fragmentos de lo almacenado en la memoria espacial y también se está conectando con el futuro, entendido como el horizonte hacia el cual se proyecta cada instante presente. Esa manipulación del tiempo vivido no sólo le otorga densidad al presente, sino que en sí misma constituye una forma de movimiento del sujeto. Si bien ello es propio de cualquier ser humano, el urbanita lo experimenta con particular intensidad por la multiplicidad de experiencias que siempre trae consigo la vida urbana.

La posibilidad de comprender y hacer inteligibles la ciudad yla vida urbana desde esta concepción del movimiento vitalista, es parte de los giros que se vienen constatando en las aproximaciones urbanas de carácter corológico y topográfico hacia otros enfoques, inacabados, de carácter topológico, que conciben el espacio como multiplicidades de flujos en movimiento, directamente ligados con las prácticas ylas performatividades delos cuerpos en movimiento.

\section{LA CIUDAD MOVIMIENTO DESDE LA COTIDIANIDAD Y LO IMAGINARIO}

La concepción de la ciudad-movimiento se funda sobre un núcleo básico, que son las prácticas espaciales de los urbanitas. Se trata de prácticas cotidianas que se espacializan, vale decir, el cotidiano hacer de las personas que se con- 
creta en lugares particulares. Pueden ser parte de cualquiera de los pequeños mundos que integran cotidianidad de los urbanitas, ya sean prácticas propias de la vida doméstica, de la vida laboral, escolar, de consumo, de ocio o de otros ámbitos cotidianos, según los sujetos considerados.

En ciertas oportunidades este énfasis en las prácticas espaciales ha sido considerado como parte nodal de las geografías de la vida cotidiana (Lindón, 2006). Kirsten Simonsen ha sido enfática al subrayar que nada en el mundo social es antes que las prácticas; ni la conciencia, ni las ideas, ni los significados, ni las estructuras, ni los mecanismos, ni los discursos, ni las redes, ni los acuerdos (Simonsen, 2007). Por su parte, Benno Werlen (1992) también confiere notoria centralidad a las prácticas en su relación con el espacio. Incluso denomina a esta aproximación geografía de las prácticas. Michel Lussault y Mathis Stock Mathis (2010) de igual forma han insistido en la centralidad de las prácticas, y denominan pragmática del espacio a su aproximación organizada en torno a las prácticas.

Por otra parte, toda perspectiva espacial centrada en las prácticas reconoce que siempretienen sentido. Las personas hacen ciertas prácticas porque buscan algo en ese hacer. En otras palabras, detrás del hacer existen motivaciones y en el hacer mismo se configuran los sentidos. Esto último ha sido planteado y desarrollado extensamente por la teoría social desde los clásicos, pero también a través de voces contemporáneas. Por ejemplo: Max Weber siempre sostuvo que la acción tiene sentido. O bien, Alfred Schütz (1974) reconoció que los significados de las prácticas resultan en la intersubjetividad.

Al revisar esta cuestión del sentido-significado de las prácticas cotidianas desde una perspectiva espacial emergen dos cuestiones que no resultan menores para nuestra aproximación: Por un lado, que esos sentidos que adquieren las prácticas en el curso mismo de su ejecución suelen transferirse a los lugares en los cuales se anclan las prácticas. Así, los lugares también adquieren densidad. Anne Buttimer, en los años setenta, ya advertía que las personas en su cotidiano actuar (las prácticas) van sellando los lugares con intenciones, valores y memo$\mathrm{ria}^{3}$. Por otro lado, la motivación para realizar cierta práctica o el sentido que se le confiere, frecuentemente procede del lugar asociado a dicha práctica. De modo tal que las prácticas siempre proceden de tramas de sentido, reactivan sentido y reconstruyen significados, pero todo ello está mediado constantemente por su dimensión espacial:loslugares en los que ocurrela vida práctica se dan sentido a las prácticas, y las prácticas reconstruyen el sentido delos lugares. En una perspectiva afín a ello, Paul, Hoelscher y Till (2001) plantean que es en estas dinámicas que los lugares adquieren textura. Así, se ha planteado la existencia de lugares de memoria (a veces son individuales, a veces colectivos) en

3 De manera precisa, Anne Buttimer planteaba que "en la vida cotidiana las personas pueden conquistar, defender, explorar y utilizar diversos lugares, que constituyen así su espacio vivido, y es en esta vida práctica, que van depositando en esos lugares intencionalidades, valores y la memoria" (1976, p. 284). 
referencia a la capacidad de los lugares de recordar hechos que allí ocurrieron, y la memoria del lugar le da un carácter particular al lugar y se constituye en vehículo de cierto significado.

A fin de comprender los procesos de construcción social de la ciudad movimiento no es suficiente con analizar las prácticas cotidianas espacializadas y sus significados. Es conveniente integrar este nivel de la pragmática espacial con aquello que se viene identificando como los imaginarios urbanos. Si bien los significados de las prácticas espacializadas pertenecen al ámbito de la subjetividad espacial y los imaginarios también, no pueden ser asimilados unos a los otros, ya que los primeros le dan sentido a diversos haceres, mientras que los segundos son mundos de sentido más amplios.

Losimaginarios urbanos son aquellas tramas subjetivas, fantasiosas, acerca de la ciudad y la vida urbana. Al concebirlos como una trama subjetiva, se está enfatizando que se trata de diversos elementos que están entretejidos por el sentido común y la imaginación en una secuencia que conlleva devenires. Dichos elementos son prácticas, a veces bajo la forma de rituales, junto con valores, deseos, intenciones, acontecimientos, restricciones-prohibiciones y también se pueden articular objetos, lugares, sujetos. Una característica relevante es que estas tramas subjetivas y espacializadas que asumen los habitantes de un lugar, no siempre proceden de objetos, sujetos, acontecimientos o las prácticas desplegadas in situ. En ocasiones derivan de fenómenos y conjuntos de prácticas que en ese lugar se realizaban en otro momento histórico. También pueden resultar de hechos, objetos, sujetos y conjuntos de prácticas que se desarrollan en otros lugares. Dicho de otra forma, algo característico de los imaginarios sociales, y de los imaginarios urbanos en particular, es que pueden proceder de cotidianidades distantes en el tiempo y/o espacio. Por eso resulta central su carácter "no representacional". Tal como planteara Castoriadis (1993), los imaginarios pueden evocar objetos, sujetos, lugares o situaciones que están ausentes por diversas razones: ya sea porque nunca estuvieron presentes o porque estuvieron presentes anteriormente y luego dejaron de estar (Lindón, 2008). Esto los distingue del significado de una práctica, ya que este último siempre se configura en el desarrollo de la práctica en cuestión. Por todo ello, tal como plantea Castoriadis (1993), el imaginario es la incesante y esencialmente indeterminada creación socio-histórica y psíquica de figuras, formas e imágenes que proveen contenidossignificativosy se entretejen en las estructuras simbólicas de la sociedad. Además, tienen la capacidad de desplazarse en el tiempo y en el espacio, migran de una ciudad a otra, de un país a otro, y también a través del tiempo.

Por esa cuasi ubicuidad que es propia de los imaginarios urbanos, pueden no representar ningún fenómeno local y, paradójicamente, modelar las prácticas cotidianas de los sujetos locales. Le dan inteligibilidad a la ciudad a través de su capacidad para configurar y distribuir entre los habitantes de la ciudad, instrumentos de percepción y comprensión de la realidad urbana 
(Lindón, 2008).Por esa puesta en circulación social de esquemas de percepción y comprensión del mundo, los imaginarios urbanos inducen ciertas prácticas o inhiben otras: son actantes.

En ocasiones, los imaginarios urbanos se presentan como fantasías urbanas proyectivas, cuando están totalmente dominados por el futuro. En otras ocasiones se presentan como fantasías urbanas retrospectivas. En este último caso, resultan de complejas articulaciones entre el pasado - a través de la memoria espacial del habitante- y el futuro, que le da el carácter fantasioso. En ambos casos, los imaginarios urbanos pueden ser radicales o derivados, para utilizar las expresiones de Castoriadis. Los imaginarios radicales resultan de la imaginación creativa de los individuos e inducen el cambio social. Los imaginarios derivados resultan del apoderamiento que la sociedad hace de la imaginación de los individuos y favorecen la reproducción social. A veces, estos dos tipos de imaginarios urbanos se conocen como imaginarios de la resistencia y la dominación (Lindón \& Hiernaux, 2008).

Estas tramas subjetivas, que están imbricadas en las estructuras simbólicas de las sociedades, denominadas imaginarios urbanos, emergen y manifiestan su capacidad para configurar la acción en el despliegue cotidiano de las prácticas. De esta forma, al concebir la construcción social de la ciudad movimiento a través de las prácticas cotidianas espacializadas, con significado e inmersas en los diversos imaginarios urbanos, se "dignifica lo cotidiano", en el sentido que le diera Lefebvre (1981) a esta expresión. Así, las cotidianidades urbanas se presentan como formas particulares de cierta historicidad. La vinculación entre la vida cotidiana urbana y la construcción histórica de las sociedades urbanas se puede seguir a través de los imaginarios urbanos. De esta forma, en nuestra aproximación, las prácticas cotidianas, sus significados y los imaginarios urbanos constituyen una trilogía fundante de la ciudad movimiento.

\section{LA CIUDAD MOVIMIENTO DESDE LA AFECTIVIDAD ENCARNADA}

Las prácticas de la vida cotidiana - con los significados que las acompañan y los imaginarios en los que pueden entretejerse- son esenciales para comprender la ciudad movimiento, aunque resultan incompletas si no se considera la afectividad encarnada que acompaña al hacer en todas sus formas. Etimológicamente, el vocablo "afecto" deriva del latín afficere, que significa influir, obrar sobre alguno, afectar. Por ello, el afecto es, en primera instancia, algo que influye en el yo y que se materializa en el cuerpo, pero también puede referir a lo que influimos en los otros a partir de cierto afecto presente en nuestro cuerpo.

Para Patricia Clough (2008), desde una perspectiva deleuziana, el afecto refiere a las capacidades del cuerpo para afectar y ser afectado, y esto incluye la sensibilidad, el dominio de lo emocional y la vida misma. Sin pretender tratar como sinónimos a la afectividad y las emociones, se reconoce que es difícil des- 
lindar unas de otras. Algunos autores han hecho intentos por diferenciarlas. Por ejemplo, Nigel Thrift (2008) parece inclinarse por concebir a los afectos como la expresión más materializada, por su carácter corporal, mientras que a las emociones se las ubica en el plano de la experiencia subjetiva del afecto. En cambio, Ben Anderson considera que carece de interés diferenciar los afectos y las emociones, y opta por concebirlos de manera integrada y holística. Su concepto de atmósferas afectivas integra lo material y lo subjetivo, los afectos y las emociones (2009). Las emociones - siempre corporizadas-implican movimientos corporales que derivan de alteraciones en el flujo sanguíneo ante las experiencias espaciales.

\begin{abstract}
Las emociones son una estrategia biológica adaptativa, valorativa de nuestro entorno; estrategia con la que el sujeto valora el mundo en el que vive de modo inmediato y pre-racional, de un modo simplemente vivido y no pensado, favoreciéndose así en él, una respuesta también inmediata, rápida, no premeditada, automática, de la que el sujeto ni siquiera tiene conciencia (Pintos Peñaranda, 2010, p. 149).
\end{abstract}

Posiblemente, para la comprensión de lo urbano quizás resulta más relevante considerar la relación entre las afectividades/emociones y la corporeidad. Y en este sentido resulta de interés recordar el planteamiento de Maurice Merleau-Ponty, aunque en ese caso el objetivo era comprender la percepción del entorno (y no a la afectividad/emociones que aquí nos ocupan). El filósofo francés observaba que las cosas (el mundo externo al ser humano) se encarnan en nosotros por nuestra percepción. Por ello, no son un puro objeto percibido (es decir, externo y reconocido), sino cosas que se encuentran enraizadas en nuestro cuerpo, están articuladas a la estructura misma de nuestra percepción. El afuera y el adentro, el interior y el exterior, se encuentran en una relación de implicación recíproca (Merleau-Ponty, 1984). Si bien Merleau-Ponty planteaba esto con relación a la percepción de las cosas, es posible retomar de su reflexión la idea acerca de que lo externo se encarna en el sujeto, se inscribe en el cuerpo. Si esta concepción era válida con relación al mundo externo de las cosas, más aún lo puede ser para la afectividad, que en esencia es del ámbito emocional y de las sensaciones.

Con un énfasis espacial, y tomando las teorías no representacionales $(\mathrm{TNR})^{4}$, nos interesa concebir el afecto como una sensación escénica no discursiva que se mueve de un cuerpo a otro (Thrift, 2008). El encuadre escénico

4 Las Teorías No Representacionales (TNR) han sido desarrolladas desde la Geografía Cultural anglosajona -particularmente por Nigel Thrift, 2008; pero también han aportado otros autores, como Ben Anderson (2010)-y tienen fundamentos en el pensamiento clásico de Baruch Spinoza y en otros contemporáneos de Gilles Deleuze, así como de Bruno Latour. Inicialmente, Thrift las nombró como “Teorías de las prácticas” (1999). Sin lugar a duda, las TNR surgieron como una crítica al "carácter representacional” (el objeto y su expresión en el espejo), tan arraigado en las diversas ciencias sociales y en la filosofía misma, y particularmente vigoroso en la geografía. En este último campo del saber, lo representacional ha tenido raíces más hondas, porque además del sentido amplio y aceptado, se reforzó por la vía de la representación cartográfica. 
del afecto es una referencia a lugares concretos en los que algo está en juego entre los actores. Al mismo tiempo, lo escénico también refiere al carácter situacional y circunstancial del afecto. El componente no discursivo indica que el afecto es previo a la conciencia, que siempre va involucrada en el lenguaje. Quizás sería más preciso plantearlo como pre-discursivo, antes que como no discursivo en tanto la afectividad se presenta antes que se formalice un discurso al respecto.

Otro aspecto relevante de esta concepción de la afectividad es su carácter circulatorio entre los cuerpos de un espacio-tiempo: la afectividad es social, porque va más allá de un individuo, pasa de un cuerpo al otro en la proximidad que ofrece el escenario urbano. La circulación de la afectividad entre los cuerpos genera tipos de performatividades o dramatizaciones, que son materializaciones efímeras de esa afectación ${ }^{5}$. De esta forma, la afectividad contribuye a la construcción socioespacial del lugar porquelas corporeidades hacen puestas en escena, que le dan un tono particular al lugar en cierto momento.

En el espacio público densamente habitado es frecuente observar en un lugar y en un momento dado, ante un acontecimiento particular, como varios sujetos, aún desconocidos entre sí, experimentan y comunican corporalmente algo semejante. Un ejemplo son aquellas performatividades de la constricción, o bien las del alejamiento, o las de la protección/autoprotección. Las performatividades de la constricción son aquellas en las cuales los cuerpos parecen hacerse más pequeños de lo que son ante el acontecimiento que está ocurriendo. Las segundas, las del alejamiento, son las que expresan un deseo de distanciamiento casi instantáneo de cierto foco de acontecer, aun cuando el alejamiento físico sólo pueda ser escaso. Las performatividades de la protección/autoprotección son las que intentan restarle visibilidad y/o exposición al propio cuerpo, valiéndose de objetos, de otros cuerpos o de formas espaciales del lugar o de la misma corporeidad. Estas afectividades se inician por algo externo al sujeto que lo afecta, pero lo relevante es que se encarna (o se inscribe) en su cuerpo y genera un movimiento corporal particular. Otro ejemplo de performatividad constructora del espacio y al mismo tiempo construida por el lugar es la dramatización de las diferentes distancias sociales en los diversos espacios urbanos y entre distintas alteridades. Y es en ese proceso constante de actuar y dramatizar corporalmente esa actuación, en y con el espacio de vida $\mathrm{y}$ con los otros que lo habitan en ese instante, que el espacio adquiere rasgos

5 El concepto de performatividad fue planteado inicialmente para dar cuenta de la capacidad del lenguaje para construir la realidad social (Austin, 1998). El discurso produce lo que nombra por su necesaria vinculación con la acción. Por ello, la performatividad ha expresado la simultaneidad entre la palabra y la acción dentro de cierto contexto que lo autoriza. Con posterioridad a los desarrollos Austin (1998) y Searle (1986; 1997), el concepto de performatividad ha sido ampliado, replanteado, resemantizado. Así, se pasó del énfasis en lo discursivo a un acento en los actos, en el hacer. Y luego, el acento comportamental hizo posible darle visibilidad a la componente corporal de lo performativo, ya que el actuar requiere de la motricidad y la expresividad del cuerpo. Entonces, la performatividad pudo dar cuenta de los actos corporales -y no sólo de los actos- que construyen la realidad. En este sentido, Víctor Turner (1974) ha replanteado la performatividad como un hacer y dramatizar corporalmente lo social y en acerca del espacio social de la ciudad. 
particularesyentra en un proceso de constantehechura por parte delos sujetoscuerpos $^{6}$ que lo habitan.

Las afectividades, en sí mismas, hacen y deshacen los lugares de la ciudad en cada instante porque los configuran en cuanto a las formas de sentir en ellos $\mathrm{y}$ a las formas de comportarse; en suma, a las puestas en escena. Por ello, las afectividades se materializan en performatividades y prácticas. Así, la afectividad corporizada "acontece" y se territorializa en cuanto a sus disposiciones o formas de hacer. La afectividad deviene parte de la construcción social del espacio urbano porque las formas de actuar y dramatizar cada instante hacen al lugar de maneras peculiares. Y es mediante la corporeidad (el cuerpo y lo que él expresa en cada situación) que el individuo se apropia del espacio y el tiempo que le acontece, lo transforma y le da cierto valor.

Un rasgo característico de estas afectividades es la simultaneidad entre la producción de la emoción-sensación no discursiva, su movimiento, la circulación entre las corporeidades y su territorialización. Usualmente, dicha simultaneidad se identifica con la expresión anglófona de enacted (o lo enactuado), en referencia a aquello que por esa simultaneidad y multidimensionalidad no se puede separar en partes ni en etapas, ni en lo que precede y lo que sucede.

El carácter situacional de las afectividades/corporeidades encuentra en su reverso la condición propia de cada lugar, en constante proceso de construcción social. En este horizonte, los lugares no se identifican exclusivamente por formas espaciales duraderas, tampoco por significados fuertes y perdurables, como sucede por ejemplo con los llamados lugares de memoria ${ }^{7}$. En la ciudad movimiento, los lugares devienen inestables y contingentes, tal como lo son las prácticas y las afectividades/performatividades que van aconteciendo en ellos. Ello no es obstáculo para que ese carácter situacional de los lugares pueda ser repetitivo, rutinizado o se integre en ciertos ritmos urbanos que se reproducen.

\section{LOS ESCENARIOS URBANOS Y LAS REDES TOPOLÓGICAS}

Tantolas prácticas cotidianas y sus significados comolosimaginarios urbanos que en ellas emergen se activan y reconfiguran, son múltiples, heterogéneos y están inscritos en el devenir cotidiano y sus ritmos, así como en los diversos lugares que constituyen la superficie topológica de la ciudad. De esta forma, esta complejidad urbana (prácticas, significados e imaginarios) solo puede

6 Se toma la expresión sujeto-cuerpo de David Seamon (1980); quien, a su vez, se inspira en Maurice Merleau Ponty. Este concepto da cuenta del proceso de inscripción en el cuerpo de ciertos saberes prácticos, que llevan a la repetición espontánea de diversas rutinas, que Seamon ha denominado body-ballets.

7 Un ejemplo que se observa en la Ciudad de México es el caso del emblemático sitio que lleva por nombre la Plaza de las Tres Culturas, de Tlatelolco. Es ampliamente conocido que este lugar, además de la carga simbólica prehispánica, ha sido construido como lugar de memoria del movimiento estudiantil de 1968 y de la famosa matanza del 2 de octubre de 1968. Sin embargo, actualmente, para los jóvenes que allí practican el skateboarding, el lugar ha sido resignificado por sus aptitudes para esta actividad. Ello no impide que para otros sujetos-habitantes, con biografías más ligadas al movimiento estudiantil de 1968, mantenga aquella carga simbólica que para muchos lo hizo un particular lugar de memoria. 
ser aprehendida empíricamente de manera parcial en fragmentos espaciotemporales: los escenarios urbanos.

Los escenarios urbanos de la ciudad movimiento son unidades espaciotemporales, a veces fugaces, otras veces con cierta duración cotidiana acota$\mathrm{da}$, en otros casos repetidos con cierta frecuencia, en ocasiones en lugares de amplia visibilidad y en otras ocasiones de visibilidad parcial y restringida, en los cuales se encuentran algunos habitantes de la ciudad conocidos entre sí y también desconocidos. Allí se realizan prácticas individuales o colectivas, se ponen en juego saberes respecto a qué hacer, cómo interpretar a los otros y cómo comportarse; se instauran proxemias y diastemias (Lindón, 2013), tanto físicas como sociales, en donde todos esperan que ocurra algo. En estricto sentido, todos los escenarios urbanos son únicos. Aunque también se debe notar que repetitivamente se reproducen escenarios semejantes, aunque cambien los actores, los lugares específicos y los fragmentos de tiempo en los que ocurren. En cualquier caso, el horizonte de esta aproximación radica en pensar a la ciudad y la vida urbana en constante proceso de hacerse y rehacerse. Y ello ocurre en los escenarios urbanos. Si bien en la concepción de los escenarios urbanos está presente un componente de inspiración goffmaniana, que incluye lo discursivo, también se integra lo inestable y lo contingente.

Así, los escenarios urbanos son fragmentos densos de la cotidianidad urbana en los cuales fluye el movimiento de la ciudad. Si la ciudad se hace en cada instante de infinitos escenarios, además ocurre que cada escenario también es una forma particular de movimiento, a diferencia de una fotografía que congela la vida urbana.

Los escenarios urbanos también ofrecen el interés de captar lo cotidiano y los significados en términos situados. Como han planteado las teorías de la cognición situada ${ }^{8}$, los individuos que actúan (y las prácticas que despliegan en el actuar) no pueden ser separados del mundo social de la acción (Lave, 1997) ${ }^{\mathbf{9}}$. Precisamente, es en los escenarios urbanos donde emergen y se reconstruyen los mundos sociales de la acción. La condición situada no deriva del escenario en tantolocalización concreta del lugar, sino de todo lo previamente mencionado como propio del escenario: lo que allíse pone en juego, las afectividades que en él circulan y se materializan en performatividades peculiares. Ben Anderson plantea el concepto de atmósferas afectivas brumosas, integrando lo material de la corporeidad y lo subjetivo asociado a la corporeidad, es decir, los afectos y las emociones (Anderson, 2009;2010). Los escenarios urbanos que planteamos no son atmósferas afectivas en el sentido de Anderson, pero ellas están presentes en cada escenario y le imprimen cierto tono particular.

8 Las teorías de la cognición situada partieron de los aportes iniciales de Lev Vigotsky, y han mantenido un núcleo clave en torno a la relación entre el individuo y su mundo social.

9 Nos referimos al conocimiento situado en el rumbo desarrollado por el pensamiento feminista, desde los años ochenta y en los noventa y de manera particular, en la perspectiva Donna Haraway (1995). 
Los escenarios urbanos se hacen y se deshacen al ritmo de la ciudad. Son relevantes porque registran instantes de las formas del movimiento urbano. En el reverso de esa riqueza se halla la inevitable fugacidad, como algo inherente a los escenarios urbanos. Por esa misma temporalidad breve que los caracteriza, los sujetos que le dan vida a un escenario, unos instantes después se hacen parte de otros escenarios. Si esto se considera desde la perspectiva de la ciudad como un todo, es posible concebirla como un conjunto infinito de fragmentos o de escenarios fugaces. Sin embargo, si se considera desde la perspectiva de los sujetos-habitantes de la ciudad y sus lugares, se presenta una perspectiva más profunda que la infinidad de fragmentos sueltos: surgen las redes topológicas, por las que circulan afectividades, sentidos, significados e imaginarios urbanos, y también saberes y formas de actuar.

Estas redes topológicas constituyen el conjunto de los lugares que cada individuo ha podido frecuentary dibujan los contornos de su mundo. Loslugares que integran la red topológica de cada sujeto llevan las marcas de quienes han sido parte de esos lugares y de los escenarios que en ellos se instalaron.

Las redes topológicas de los sujetos habitantes de la ciudad siempre son extensivas y retráctiles en el contexto de sus las trayectorias biográficas: en algunos momentos de la biografía del sujeto, las redes topológicas se extienden a más lugares y en ocasiones, a lugares más distantes de su centro espacial. Y en otros momentos de la biografía, las redes topológicas de un individuo se restringen, se reducen en extensión, en lugares, en actividades y en alteridades. Este carácter, extensivo y retráctil, se relaciona con el movimiento vitalista que mencionamos al inicio, es decir, con el flujo cotidiano de la vida de cada sujeto.

Un rasgo propio de las redes topológicas es el entrecruzamiento de las de un habitante con las de otro. Como planteara Pred $(1981,2005)$, siguiendo la perspectiva de Hägerstrand (1982), los encuentros de unos individuos y otros ocurre en el contexto de proyectos más o menos institucionalizados que los acercan, los conectan o simplemente los colocan en cercanía física. Con este horizonte es posible identificar los lugares (con sus respectivos escenarios) que conforman la red topológica de una persona, y los proyectos institucionalizados que están presentes en cada escenario ${ }^{10}$.

Esas redes topológicas de diversos habitantes, al entrecruzarse, dibujan la textura de la ciudad con los encadenamientos de espacios de vida de cada sujeto, que integran los lugares habitados por el sujeto en el presente, en momentos biográficos previos y los lugares aun no habitados por el sujeto, pero que imagina habitar en el futuro, y que por ello los conecta, al menos, con los del presente. Esos lugares habitados por cada sujeto han sido construidos socialmente de maneras particulares por quienes allí han estado, y a su vez los lugares han contribuido a identificar a los sujetos. En estos espacios de vida

10 Nos referimos a lo institucionalizado en el sentido más amplio posible. 
interconectados, los sujetos construyen incesantemente acercamientos a unos (en los cruces con sus redes topológicas), y alejamientos de otros (las áreas y sujetos que las redes topológicas eluden, y dejan como vacíos de experiencias espaciales).

\section{REFLEXIONES FINALES}

Este artículo ofrece una aproximación a la ciudad y a la vida urbana desde ángulos poco explorados en los estudios urbanos, todos anclados en el concepto de movimiento en una perspectiva vitalista. Quizás la escasa atención que se ha prestado a estos ángulos en los estudios urbanos se deba al carácter escurridizo que tiene todo aquello que se mueve. En este sentido, el artículo tiene un objetivo implícito: poner en tela de juicio las certezas inmovilizadoras y cosificadoras que han sido rectoras en el estudio de la ciudad. Por ello, se parte de críticas que en diversas ocasiones se han formulado a esas certezas. Quizás una de las más emblemáticas ha sido la reflexión de David Ley (1987), cuando rechazaba la "Geografía del Homo Dormiens"11. Si bien Ley criticaba directamente los acercamientos a la ciudad realizados desde la geografía urbana, lo mismo podría plantearse con relación al campo amplio de los estudios urbanos.

El intento de conocer la ciudad y lo urbano desde el movimiento vitalista trae consigo el reconocimiento dela imposibilidad de conocer la ciudad en toda su extensión, que también ha sido una premisa largamente aceptada. Estudiar una ciudad en extensión, aunque fuese una ciudad de escasas dimensiones, solo es posible con sucesivas reducciones. Una de las más relevantes es reducir el espacio vivido al espacio material, al espacio de las localizaciones de personas y objetos, aun cuando se reconozca que esa materialidad resulta de procesos históricos.

Al considerar la ciudad desde el movimiento, la mirada aérea o icariana, tan legitimada para el estudio de la ciudad, parece dejar de ser una herramienta pertinente por su imposibilidad para integrar la perspectiva del sujeto que habita los escenarios urbanos y por anular el movimiento vitalista, el fluir de lo cotidiano.

Las estructuras urbanas, sean formas espaciales u otras, asícomo las estructuras socio-culturales, son contextos que limitan, potencializan o condicionan el flujo de la cotidianidad de la ciudad. Pero por si solas no generan la vida urbana, no tienen consecuencias (buscadas y no buscadas) hasta que no se hacen parte de la cotidianidad de los habitantes de la ciudad. Pero son las estructuras

11 La expresión geografía del Homo Dormiens procede de un texto de Patrick Crowe(1938). Una expresión del estudio de la ciudad del Homo Dormiens es el interés por la morfología urbana y la conocida estrategia de subdividir el espacio intraurbano en función de los niveles socio-económicos de los residentes de los diferentes barrios de una ciudad, o de subdividir la ciudad según tipos de actividades económicas. Son claros ejemplos de inmovilizar con el tipo de acercamiento, lo que en esencia se está recreando constantemente. 
urbanas, particularmente las formas espaciales, las que pueden ser representadas en las miradas aéreas, es decir, la materialidad sin el fluir cotidiano.

En cambio, en la propuesta aquí presentada se revaloriza el conocimiento de fragmentos de ciudad, inestables y cambiantes en el tiempo, incluso en el ciclo cotidiano. Estos fragmentos no tienen por qué ser contiguos, tampoco continuos espacialmente. Estos fragmentos inestables son los escenarios urbanos (Lindón, 2010). De esta forma, la concepción de la ciudad presentada en las páginas previas deja atrás las miradas corológicas (que describen desde arriba los fenómenos que se suceden en la extensión espacial) y topográficas (que describen las localizaciones de fenómenos en un lugar), para explorar las perspectivas topológicas. De igual forma, nos alejamos de los enfoques paralos cuáles las ciudades albergan poblaciones (es decir, agregados de individuos) que manufacturan el hábitat urbano. En cambio, nos instalamos en las concepciones del espacio urbano habitado por sujetos móviles que se apropian y disputan fragmentos de espacio urbano, los hacen suyos, los marcan, inscriben en ellos sus biografías y también los abandonan otras veces, para habitar otros lugares. Estos sujetos móviles no sólo son homo faber, sino también sujetocuerpo y sujeto-sentimiento, que se encuentran con otredades buscadas y con otras no buscadas ni deseadas, y que van sellando sus espacios de vida con acontecimientos biográficos, con sueños, fantasías, miedos, rechazos, valores, ideas e imágenes.

En esta perspectiva, nuestra concepción de la ciudad parte de la cotidianidad. Ello supone colocar en el centro al sujeto habitante en su constante hacer, en las prácticas cotidianas con las cuales habita los lugares. Nuestra perspectiva integra como parte de la cotidianidad los significados que las personas le otorgan a sus prácticas y también esas amplias tramas de sentido denominadas imaginarios urbanos, que de alguna manera colonizan la cotidianidad; o en otras ocasiones se resisten a las ideas y las formas de vida colonizadas. No resulta inesperado que el estudio de la ciudad haya demorado tanto en integrar la vida cotidiana, cuando la filosofía misma, durante muchos años la menospreció.

Nuestro segundo nivel de análisis de la ciudad y lo urbano se ancla en las afectividades, las emociones y la corporeidad. Si la vida cotidiana demoró en ser aceptada como una entrada relevante para comprender la ciudad, las afectividades, emociones y corporeidades aún no lo han logrado. Apenas empiezan a filtrarse como ventanas adecuadas para la comprensión de lo urbano. El análisis de cada uno de estos dos niveles analíticos (la cotidianidad con la correspondiente subjetividad, y la afectividad/corporeidad) siempre ofrecerá empíricamente aspectos relevantes e inesperados. Pero, aun así, la perspectiva no se encuentra cerrada a estos dos niveles. Más bien los consideramos dos entradas necesarias para comprender la ciudad movimiento, pero podrán ser enriquecidos con otros. 
Dado que nuestro abordaje de la ciudad es desde la densidad de cada experiencia espacial, lo anterior no encuentra mejor conjunción que en la perspectiva situacional de los escenarios urbanos. La cotidianidad, la subjetividad y los imaginarios se entrecruzan con las afectividades y las corporeidades en los diversos escenarios urbanos que permiten el encuentro de sujetos en un espacio-tiempo y en el contexto de un proyecto institucional, aun cuando este último sea banal, como por ejemplo la espera de un medio de transporte. Que en cierto lugar del espacio público se concentren personas esperando la llegada del medio de transporte, muestra que allí se ha estructurado y materializado un proyecto institucional de movilidad urbana. Así, los escenarios urbanos adquieren una capacidad integradora de lo urbano por permitir la convergencia de los dos niveles analíticos considerados: en un fragmento de tiempo, ese fragmento de espacio articula sujetos, prácticas, significados, ideas, fantasías y proyecto institucional.

La perspectiva acerca delo urbano se profundiza cuando el análisis traspasa la lógica del instante, en la que ocurre la puesta en escena (el escenario urbano) e incorpora el tiempo vivido en el pasado (la memoria espacial) y el tiempo imaginado por los sujetos (las fantasías espaciales): las redes topológicas de cada habitante de la ciudad. Las redes topológicas de los habitantes de la ciudad construyen la ciudad como espacio vivido a través de las biografías espacializadas de las personas. Estas redes topológicas son los mecanismos por los cuáles unos lugares de la ciudad reproducen características de otros, o bien, se diferencian de otros lugares. Las redes topológicas son los canales por los cuales circulan los sentidos de los lugares: así, el sentido atribuido a un lugar, por ejemplo, como espacio de la seguridad y la protección, es atribuido a otro lugar, aun cuando sea distante físicamente del anterior. Las redes topológicas permiten la circulación de saberes espaciales, de formas de actuar y dramatizar lo social y los sentidos de los lugares. Esa circulación es posible porque ocurre a través de las biografías de los urbanitas. Lo vivido por un sujeto en cierto momento de su trayectoria biográfica es rememorado y activado en un tiempo posterior y en un lugar, quizás distante.

De esta forma, los escenarios urbanos, que en una primera mirada podrían parecer excesivamente situacionales, en realidad presentan la profundidad de lo vivido en otros lugares y otros momentos, pero que es traído al presente del escenario y le permite al sujeto que actúa en el escenario contrastar esa situación con otras vividas. El carácter holístico de toda biografía también se expresa en la fusión particular de la corporeidad y la emocionalidad: no sería posible concebir una biografía sin un cuerpo que la protagonice y en el que se encarnen las acciones cotidianas. La corporeidad de toda biografía no es sólo un sustrato material y móvil de la vida, sino también lo que permite al sujeto sentir y constituirse en un sujeto-sentimiento que experimenta los espacios de vida con las correspondientes otredades. 


\section{REFERENCIAS}

Anderson, B. (2009). Affective atmospheres. Emotion, Space and Society, 2, (2), pp. 77 81. En línea: http://dx.doi.org/10.1016/j.emospa.2009.08.005

Anderson, B. (2010). Taking-Place: Non-Representational Theories and Geography. Londres: Routledge.

Austin, J. L. (1998). Cómo hacer cosas con las palabras. Barcelona: Paidós.

Butler,J.(1988).PerformativeActsandGenderConstitution:AnEssayinPhenomenology and Feminist Theory. Theatre Journal, 40, (4), pp. 519-531.

Buttimer, A. (1976). Grasping the dynamism of lifeworld, Annals of the American Geographers, 66, (2), pp. 277-292.

Castoriadis, C. (1993). La institución imaginaria de la sociedad, vol. 2. El imaginario social y la institución. Buenos Aires: Tusquets.

Clough, P. (2008). (De)coding the Subject-in-Affect. Subjectivity, 23, (1), pp. 140-155. En línea: http://dx.doi.org/10.1057/sub.2008.16

Clough, P. \& Halley, J. (eds.) (2007). The Affective Turn: Theorizing the Social. New York: Duke University Press Books.

Crowe, P. R. (1938). On progress in Geography. Scottish Geographical Magazine, 54, pp. 1-19. En línea: http://dx.doi.org/10.1080/14702543808553767

Davidson, J., Bondi, L. \& Smith, M. (2007). Emotional Geographies. Eds. Hampshire, GB: Ashgate Publishing Ltd.

Ezcurdia,J.(2013). Amor, cuerpo y filosofía dela experiencia: hacialalectura deleuziana de Bergson. EN-CLAVES del pensamiento, año VII, 14, julio-diciembre 2013, pp. 145-176.

Hagerstrand, T. (1982). Diorama, Path and Project. Tijdschrift voor economische en sociale geografie, $73,(6)$, pp. 321-384.

Haraway, D. (1991). “Conocimientos situados: La cuestión científica en el feminismo y el privilegio de la perspectiva parcial”; en Donna H., Ciencia, cyborgs y mujeres. La reinvención de la naturaleza, pp. 313-345, Madrid: Ediciones Cátedra [1991, Simians, Cyborgs and Women. The Reinvention of Nature. London: Routledge].

Harvey, D. (1998). La Condición de la posmodernidad: investigación sobrelos orígenes del cambio cultural. Buenos Aires: Amorrortu.

Honoré, C. (2005). Elogio de la Lentitud. Barcelona: RBA.

Ibáñez, J. (1994). El regreso del sujeto: la investigación social de segundo orden, Madrid: Siglo XXI. 
Lave, J. (1997). The culture of acquisition and the practice of understanding, en: Kirshner, D. y Whitson J.A. (Eds.) Situated cognition: Social, semiotic and psychological perspectives, pp. 17-35, Mahwah, New Jersey: Lawrence Erlbaum Associates.

Lefebvre,H.(1981). Critiquedelaviequotidienne. Vol.III:Delamodernitéaumodernisme (Pour une métaphilosophie du quotidien). Paris: L'Arche Editeur.

Ley, D. (1983). A Social Geography of the City. New York: Harper \& Row Publishers.

Lindón, A. (2006) Geografías de la vida cotidiana. En Lindón A.; Hiernaux, D. (dir.), Tratado de Geografía Humana, pp. 352 - 396, Barcelona: Anthropos-UAMI.

Lindón, A. (2008). El imaginario suburbano: entre los sueños diurnos y la reproducción socio-espacial de la ciudad. Revista Iztapalapa. Universidad Autónoma Metropolitana, Iztapalapa, nº 64-65, año 29, pp. 39-62.

Lindón, A. \& Hiernaux, D. (2008). Los imaginarios urbanos de la dominación y la resistencia: un punto de partida. Revista Iztapalapa. Universidad Autónoma Metropolitana, Iztapalapa, no 64-65, año 29, pp. 7-14.

Lindón, A. (2010). Invirtiendo el punto de vista: Las Geografías Urbanas Holográficas del sujeto habitante. En Lindón, A; Hiernaux, D (dirs.), Los Giros de la Geografía Humana: Tendencias y horizontes, pp. 175-200, Barcelona: Anthropos-UAMI.

Lindón, A. (2013). Territorialized everydayness between proxemics and diastemics: space-time rhythms in a context of acceleration. En Pirani B. \& Smith T. S. (Eds.), Body and time: bodily rhythms and social rhythms and Social Synchronism in the Digital Media Society, pp. 83-105. Cambridge: Scholars Publishing.

Lindón, A. (2015). Del cronotopo fundacional a la construcción socio-espacial del territorio vallechalquense. En Lindón A. \& Mendoza, C. (coords.), La periferia metropolitana: entre la ciudad prometida y un lugar para vivir en la ciudad de México, pp. 115-150, México: Gedisa Mexicana-UAM-I.

Lussault, M. \& Stock, M. (2010). Doing with space: towards a pragmatics of space. En Social Geography, vol. 5 (1), pp. 11-19.

Merleau-Ponty, M.(1984). Fenomenología delapercepción, Barcelona:Editorial Planeta.

Adams, P., Hoelscher, S. \& Till, K. (2001). Place in Context: Rethinking Humanist Geographies. En Textures of Places: Exploring Humanist Geographies, (pp. xiiixxxiii), Minneapolis: University of Minnesota Press.

Pile, S. (1996). The body and the city: Psychoanalysis, space and subjectivity. Nueva York: Routledge.

Pile, S. \& Thrift, N. (1995). Mapping the Subject. En Pile, S. \& Thrift N. (Eds.), Mapping the Subject: Geographies of cultural transformation, pp. 12-51. London-New York: Routledge.

Pintos Peñaranda, M. L. (2010). Fenomenología de la corporeidad emotiva como condición de la alteridad. Investigaciones Fenomenológicas, vol. monográfico 2. Cuerpo y Alteridad, pp. 141-168. 
Pred, A. (1981). Social Reproduction and the Time-Geography of Everyday Life, Geografiska Annaler. Series B, Human Geography, 63 (1), pp. 5-22. Doi: $10.2307 / 490994$

Pred, A. (2005). Hägerstrand matters: life(-path) and death matters-some touching remarks. Progress in Human Geography, 29 (3), pp. 328-332. Doi: 10.1177/030913250502900310

Schütz, A. (1974). El problema de la realidad social. Buenos Aires: Amorrortu Editores.

Seamon, D. (1980). Body-Subject, Time-Space Routines, and Place-Ballets. En: Buttimer, A.; Seamon D. (dir.), The Human Experience of Space and Place, pp. 148-165, Londres: Croom Helm.

Searle, J. R. (1986). Actos de habla. Barcelona: Ediciones Cátedra.

Searle, J. R. (1997). La construcción de la realidad social. Barcelona: Ediciones Paidós

Sheringham, M. (2006) Everyday Life: Theories and Practices from Surrealism to the Present. Oxford: Oxford University Press.

Simmel, G. (1986). Las grandes urbes y la vida del espíritu. E: Simmel, G. El individuo y la libertad: ensayos de crítica de la cultura, pp. 247-261, Barcelona: Ediciones Península.

Thrift, N.(1983). On the Determination ofSocial Action in Space and Time.Environment and Planning D: Society and Space, 1 (1), pp. 23-57.

Thrift, N. (1999). Steps to an Ecology of Place. En: Massey D., Allen J. \& Sarre P. (Eds.), Human Geography Today, pp. 295-323, Cambridge: Polity Press.

Thrift, N. (2006). Space, Theory, Culture \& Society, 23, pp.139-146, Doi: $10.1177 / 0263276406063780$

Thrift, N. (2008). Non-representational theory: space, politics, affect. London \& New York: Routledge.

Thrift, N. \& Dewsbury, J. (2000). Dead geographies and how to make them live, Environment and Planning D: Society and Space, 18, pp. 411-432.

Turner, V. (1974). Dramas, Fields, and Metaphors: Symbolic Action in Human Society, Ithaca, New York: Cornell University Press.

Weiss, G. (1999). Body Images. Embodiment as Intercorporeality. New York and London: Routledge.

Weiss, G. \& Haber, H. F. (1999). Perspectives of embodiment: The intersections of nature and culture, Londres: Routledge.

Werlen, B. (1992). Society, Action and Space: An Alternative Human Geography. Londres: Routledge. 


\section{IDENTIFICACIÓN DE LAAUTORA}

Alicia Lindón es Doctora en Sociología por El Colegio de México. Realizó la maestría en Estudios Urbanos en la misma institución y la licenciatura en Geografía en la Universidad de Buenos Aires (UBA). Es profesora-investigadora del Departamento de Sociología de la Universidad Autónoma Metropolitana (campus Iztapalapa), en el área de investigación Sociología de la Cultura, y es miembro delCuerpo Académico Espacio SocialdelaCiudad.Es miembro del Sistema Nacionalde Investigadores del Consejo Nacional de Ciencia y Tecnología (Conacyt), México, y desde 2013 se desempeña como Coordinadora del Consejo Editorial de Ciencias Sociales y Humanidades de dicha institución. Sus líneas de investigación se centran en el estudio de la dimensión espacial de lo social desde la perspectiva del sujeto habitante: "El enfoque biográfico y la subjetividad espacial", "La ciudad habitada y los imaginarios urbanos", "Las socio-geografías de la vida cotidiana" y "Espacialidades y corporalidades: Geografías Híbridas”.

\section{REGISTRO BIBLIOGRÁFICO}

Lindón, Alicia (2017). La ciudad movimiento: Cotidianidades, afectividades corporizadas y redes topológicas. InMediaciones de la Comunicación, 12(1), 107-126. 